\title{
Quantification of Total Phenolics and Curcumin Content in Different Turmeric Germplasm
}

\author{
Vishakha Burman $^{1 *}$, Vaishali ${ }^{1}$, Khyati Lehari ${ }^{1}$, Naresh Pratap Singh ${ }^{2}$, \\ Bijendra Singh $^{3}$, Pooran Chand ${ }^{4}$, Jitender Singh ${ }^{2}$ and R. S. Sengar ${ }^{1}$
}

${ }^{1}$ Department of Biotechnology, ${ }^{2}$ Department of Commercial Biotechnology, College of Agriculture, ${ }^{3}$ College of Horticulture, ${ }^{4}$ Department of Genetics and Plant Breeding, SVPUA\&T, Meerut

*Corresponding author

\section{A B S T R A C T}

\section{Keywords}

Secondary metabolities, Total phenolic content, Curcumin content

Article Info

\section{Accepted:}

12 October 2020 Available Online: 10 November 2020
Phenolics are secondary metabolites known as the natural antioxidants. They play significant role in plant defence against the pathogens, therefore used as treatment and to control the pathogenic infections in human also. Turmeric is well-known and valued medicinal plant due to the presence of natural occurring secondary metabolite. The present study aimed to evaluate the total phenolics and curcumin content from the leaves and rhizomes of turmeric germplasms. For this purpose, 30 turmeric germplasm with diverse background were used. The total phenolics were isolated from methanolic extracts of leaves and rhizome. Whereas curcumin content were only quantified from rhizomes samples. In leaves, the total phenolic content was found from minimum 89.36 $\mathrm{mgGAE} / 100 \mathrm{~g}$ to maximum $282.52 \mathrm{mgGAE} / 100 \mathrm{~g}$. On the other hand, the total phenolics from rhizomes of turmeric was found minimum $49.12 \mathrm{mgGAE} / 100 \mathrm{~g}$ to maximum 142.06 mgGAE/ $100 \mathrm{~g}$ and in rhizome extracts. The curcumin content ranged from $0.50 \mathrm{~g} / 100 \mathrm{~g}$ to $1.32 \mathrm{~g} / 100 \mathrm{~g}$ in rhizomes of turmeric.

\section{Introduction}

Turmeric belongs to the genus Curcuma is a member of the family Zingiberaceae having 2500 years old medicinal history (Namratha et al., 2013). In plants various metabolic pathways are responsible for the synthesis of variety of compounds. These compounds are generally differentiated into primary and secondary metabolites. Although to know the presences of secondary metabolites, various study have been done at the tiny extent only in small proportion of all plants species and about 100,000 plant secondary metabolites are already knows (Verpoorte et al., 2007). Phenolic compounds are synthesized in plants partly as a response to ecological and physiological pressures such as pathogen and insect attack, UV radiation and wounding (Napal et al., 2010; Kennedy and Wightman, 2011; Zulak et al., 2006; Chung et al., 2003; Vishakha et al., 2019). The basic structural feature of phenolic compounds is an aromatic ring bearing one or more hydroxyl groups 
(Chirinos et al., 2009). Therefore, in the present study aimed to analysed phytochemical constituent of $\mathrm{s}$ turmeric germplasm.

\section{Materials and Methods}

30 turmeric germplasm with diverse background were used in the present study.

\section{Phytochemical profiling of turmeric germplasm}

\section{Extraction of total phenolic compounds from turmeric germplasm}

The Total phenolic acids were extracted from the leaves and rhizomes of turmeric germplasm using the standard method (Bray and Thorpe, 1954). For this, 0.5 gm of leaf and rhizome sample was taken and homogenized in $10 \mathrm{ml} 80 \%$ methanol in a mortar pestle.

Spectrophotometric quantitative determination of total phenolics in turmeric germplasm

$0.5 \mathrm{ml}$ of the sample was mixed with $8.0 \mathrm{ml}$ double distilled water and $0.5 \mathrm{ml}$ follin ciocalteu's reagent (this was diluted 1:2 with double distilled water before use) was added. The reaction mixture was incubated for $3 \mathrm{~min}$ and then $1 \mathrm{ml}$ of $\mathrm{Na}_{2} \mathrm{CO}_{3}$ (25\% in water) was added to stop the reaction. The reaction mixture was left at room temperature for 1 hour and the absorbance was recorded at 725 $\mathrm{nm}$. The following reagents were used for quantitative estimation of phenolic compounds extracted from leaves and rhizomes of different germplasm of turmeric

\section{Quantitative analysis of Curcumin}

$1 \mathrm{gm}$ of rhizome of turmeric germplasm was weighed and made extract with methanol and made up to $100 \mathrm{ml}$. From this solution $5 \mathrm{ml}$ was pipette out and absorbance was taken out at $425 \mathrm{~nm}$ in a spectrophotometer. The Curcumin content was calculated using the following formula (Sadasivam and Manickam, 2008),

Curcumin content gm $/ 100 \mathrm{gm}=$

$\underline{0.0025 \times \mathrm{A} 425 \times \text { volume made up x dilution factor } \mathrm{x} 100}$ $0.42 \mathrm{x}$ weight of the sample (gm) x 1000

\section{Results and Discussion}

Phenolic compounds are the most abundant phytochemicals which is synthesized the plants and accumulate under adverse environmental condition. These are natural occurring antioxidant in the plants. Organic solvent extraction is the main method used to extract phenolics. Chemical procedures are used to detect the presence of total phenolics, while spectrophotometric and chromatographic techniques are utilized to identify and quantify individual phenolic compounds.

The total phenolics were analyzed from the leaves and rhizomes samples of 30 turmeric germplasm. The total phenolics from the leaves of turmeric germplasm in terms of $\mathrm{mg} / \mathrm{g}$ values are shown in Table 1 and their graphical representation are shown in Figure 1(A). In the leaves samples, the total phenolic content was found to be varied from a lower value of $89.36 \mathrm{mg} / \mathrm{g}$ in germplasm 21 and 30 to a higher value of $282.52 \mathrm{mg} / \mathrm{g}$ in germplasm 18 and 20. However other germplasm like germplasm 4, 7, 8, 10 and 13 also showed good amount of total phenolics in leaves of turmeric. Whereas the germplasm 6 showed very less amount of total phenolics in leaves of turmeric.

On the other hand, the total phenolics from rhizomes of turmeric germplasm in term of $\mathrm{mg} / \mathrm{g}$ units were shown in Table 1 and their graphical representation are shown in Figure 1(B). In the rhizomes samples, the total 
phenolics were found to be varied from a lower value of $49.12 \mathrm{mg} / \mathrm{g}$ in germplasm 25 to a higher value of $142.06 \mathrm{mg} / \mathrm{g}$ unit in germplasm 26. However in some other germplasm like germplasm $4,8,10,20,22$ and 28 were also showed a good amount of total phenolics in rhizomes of turmeric. Whereas in germplasm 5 and 15 were showed very less amount of total phenolics content in rhizomes of turmeric.
Curcumin content in methanolic extract of rhizomes of thirty turmeric germplasm were quantified in term of $\mathrm{g} / 100 \mathrm{~g}$ of rhizomes were shown in table 1 and their graphical representation are shown in Figure 1(C). In the rhizome extract of turmeric germplasm the curcumin content was found minimum $0.50 \mathrm{~g} / 100 \mathrm{~g}$ in germplasm 27 and maximum $1.32 \mathrm{~g} / 100 \mathrm{~g}$ in germplasm 20.

Table.1 Total phenolic content of 30 turmeric germplasm

\begin{tabular}{|c|c|c|c|c|}
\hline S.no & $\begin{array}{l}\text { Turmeric } \\
\text { Germplasm }\end{array}$ & $\begin{array}{l}\text { Leaves samples } \\
\text { TPCmg GAE/g }\end{array}$ & $\begin{array}{c}\text { Rhizomes samples } \\
\text { TPCmg GAE/g }\end{array}$ & $\begin{array}{c}\text { Curcumin content } \\
\mathrm{g} / 100 \mathrm{~g}\end{array}$ \\
\hline 1. & Germplasm 1 & 188.88 & 080.95 & 00.65 \\
\hline 2. & Germplasm 2 & 193.99 & 086.03 & 00.61 \\
\hline 3. & Germplasm 3 & 136.48 & 078.30 & 00.68 \\
\hline 4. & Germplasm 4 & 243.75 & 101.20 & 00.94 \\
\hline 5. & Germplasm 5 & 102.76 & 055.83 & 00.63 \\
\hline 6. & Germplasm 6 & 091.71 & 062.32 & 00.61 \\
\hline 7. & Germplasm 7 & 280.82 & 083.84 & 00.60 \\
\hline 8. & Germplasm 8 & 244.48 & 107.20 & 00.65 \\
\hline 9. & Germplasm 9 & 177.32 & 063.90 & 00.68 \\
\hline 10. & Germplasm 10 & 246.67 & 111.42 & 00.91 \\
\hline 11. & Germplasm 11 & 128.26 & 071.59 & 00.73 \\
\hline 12. & Germplasm 12 & 146.77 & 087.49 & 00.63 \\
\hline 13. & Germplasm 13 & 245.94 & 104.59 & 00.96 \\
\hline 14. & Germplasm 14 & 133.12 & 070.25 & 00.78 \\
\hline 15. & Germplasm 15 & 145.97 & 058.85 & 00.68 \\
\hline 16. & Germplasm 16 & 128.26 & 083.89 & 00.63 \\
\hline 17. & Germplasm 17 & 172.19 & 075.50 & 00.79 \\
\hline 18. & Germplasm 18 & 282.52 & 096.95 & 00.74 \\
\hline 19. & Germplasm 19 & 195.22 & 070.64 & 00.79 \\
\hline 20. & Germplasm 20 & 282.52 & 121.63 & 01.32 \\
\hline 21. & Germplasm 21 & 089.36 & 094.73 & 00.80 \\
\hline 22. & Germplasm 22 & 182.92 & 115.24 & 00.86 \\
\hline 23. & Germplasm 23 & 145.18 & 075.50 & 00.65 \\
\hline 24. & Germplasm 24 & 131.44 & 095.24 & 00.66 \\
\hline 25. & Germplasm 25 & 100.38 & 049.12 & 00.51 \\
\hline 26. & Germplasm 26 & 184.63 & 142.06 & 00.94 \\
\hline 27. & Germplasm 27 & 142.63 & 071.43 & 00.50 \\
\hline 28. & Germplasm 28 & 199.94 & 107.95 & 01.00 \\
\hline 29. & Germplasm 29 & 145.97 & 068.66 & 00.76 \\
\hline 30. & Germplasm 30 & 089.36 & 065.89 & 00.81 \\
\hline
\end{tabular}


Fig.1 Graphical Representation of total phenolic content in 30 turmeric germplasm (A)- in leaves samples and (B)- in rhizomes samples (C)-Curcumin content

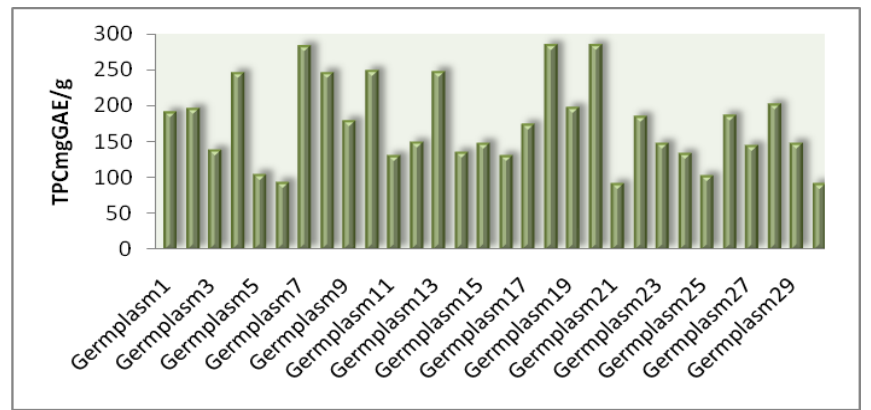

(A)

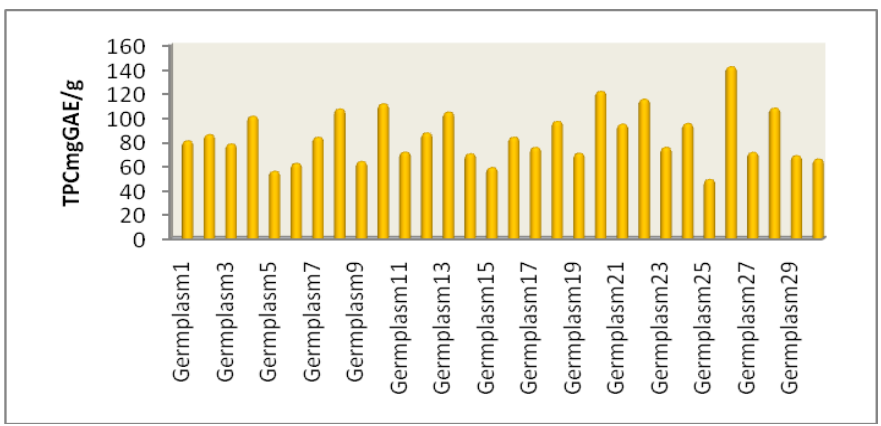

(B)

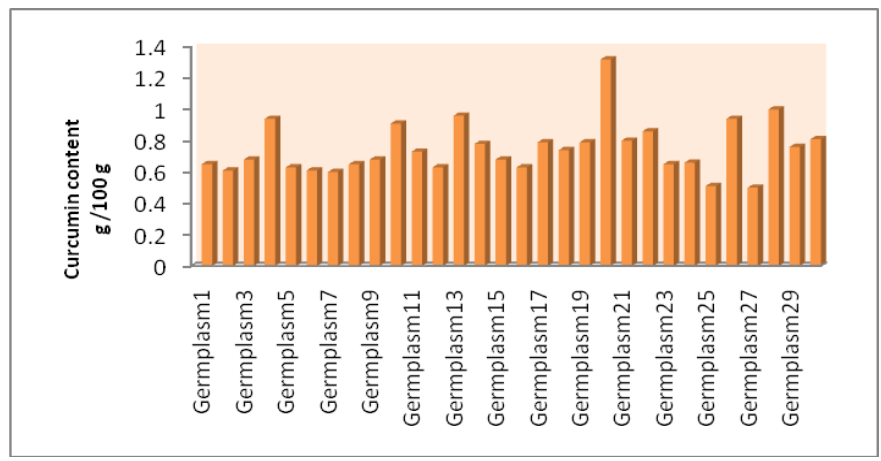

(C)

For phytochemical profiling of thirty turmeric germplasm, the total phenolics were isolated from leaves and rhizome extract. The extract was analyzed quantitatively as well as qualitatively. In the leaves samples, the total phenolic content was found a minimum of $89.36 \mathrm{mgGAE} / 100 \mathrm{~g}$ in germplasm 21 and 30 , and maximum $282.52 \mathrm{mgGAE} / 100 \mathrm{~g}$ in germplasm 18 and 20. On the other hand, the total phenolics from rhizomes of turmeric was found a minimum of $49.12 \mathrm{mgGAE} / 100 \mathrm{~g}$ in germplasm 25 and maximum 142.06
mgGAE/100g in germplasm 26.

Yan et al (2010) determine the total phenolic content from the leaf sample of turmeric and reported $348.75 \mathrm{mg}$ GAE/100g of total phenolic. Kim et al., (2019) quantified the total phenolic content in turmeric leaves. In this study, the total phenolic content was found $3.65 \mathrm{mgGAE} / \mathrm{g}$ in the turmeric leaves which is of similar range as obtained in the present study. These findings are in agreement with the present study were by a little higher amount of total phenolics may be 
due to the cell wall disruption which is responsible for stimulating the release of an oxidative and hydrolytic enzyme that would decrease the amount of some phenolics in the present study.

The leaves of turmeric are in much more because quantity the plants have a substantial volume with the large surface area makes turmeric leaves a plentiful resource. Moreover, the leaf extract of turmeric show potential as a functional source of food because of its total phenolic compound.

Kumar et al (2016) evaluate the total phenol content from the flower of Curcuma longa. They found a significant amount of phenolics $(210.45 \pm 1.32 \mathrm{mg}$ GAE/100 g) was present in the turmeric flowers also.

Similar to the present study, Maizura et al., (2011) analyzed total phenolic content (TPC) in kesum, ginger and turmeric. Their result shows that kesum had the highest total phenolic content followed by ginger and rhizome of turmeric, which is $165.34 \mathrm{mg}$ GAE/ $100 \mathrm{~g}$, $101.56 \mathrm{mgGAE} / 100 \mathrm{~g}$ and $67.89 \mathrm{mgGAE} / 100 \mathrm{~g}$, respectively. The results of this study are in accordance with the present study. Likewise, Madhusankha et al., (2018), studied total phenolic content in turmeric rhizomes. They reported total phenolic content among the turmeric ranged from 627.4 to $422.68 \mathrm{mg}$ GAE/100g which is slightly higher than the present study. A similar study has also been done by Gezici (2019). In the present study the leaf extract of turmeric elicited a relatively higher amount of total phenolic content as compare with rhizome extract which may be due to the fact that it contains more phenol compound. The difference observed in Total Phenolic Content content might be due to the number of active substances, solvent, extraction method and geographical condition for the cultivation of turmeric germplasm.

Curcumin content in methanolic extract of rhizomes of thirty turmeric germplasm was quantified. In rhizome extract of turmeric germplasm the curcumin content found minimum $0.50 \mathrm{~g} / 100 \mathrm{~g}$ in germplasm 27 and maximum $1.32 \mathrm{~g} / 100 \mathrm{~g}$ in germplasm 20 . Anjusha et al (2014) analysed the curcumin content in Curcuma aromatica and Curcuma xanthorrhiza. In this study, they reported the curcumin content was $1.0863 \mathrm{~g} / 100 \mathrm{~g}$ of rhizome in C. xanthorrhiza and $0.0175 \mathrm{~g} / 100 \mathrm{~g}$ in $C$. aromatic which is of similar range to present study. Curcumin is the major compound present in the rhizome of turmeric and is commonly used as a natural dye in food industries, cosmetics and in pharmaceutical industries. The genotypes which show high curcumin content may exhibit strong antioxidant, anti-inflammatory, antimicrobial and anticarcinogenic activity (Anand et al., 2008; Vishakha et al., 2019).

\section{References}

Anand, P., S. G. Thomas, A. B. Kunnumakkara, C. Sundaram, K. B. Harikumar, B. Sung and Aggarwal, B. B. 2008. Biological activities of curcumin and its analogues (Congeners) made by man and Mother Nature. Biochemical Pharmacology. 76:1590-1611.

Anjusha, S., and Gangaprasad, A. 2014. Phytochemical and antibacterial analysis of two important Curcuma species, Curcuma aromatic Salisb. and Curcuma xanthorrhiza Roxb. (Zingiberaceae). Journal of Pharmacognosy and Phytochemistry. 3: 50-53.

Bray, H. G. and Thorpe, W. V. 1954. Estimation of phenols. Methods of Biochemical Analysis. 1: 27-52.

Chirinos, R., I. Betalleluz-Pallardel, A. Huamán, C. Arbizu, R. Pedreschi and Campos, D. 2009. HPLC-DAD characterization of phenolic compounds from Andean oca (Oxalis tuberosa Mol.) tubers and their contribution to the antioxidant capacity. Food Chem. 113:1243-1251.

Chung I. M., M. R. Park, J. C. Chun and Yun, S. J. 2003. Resveratrol accumulation and resveratrol synthase gene expression in 
response to abiotic stresses and hormones in peanut plants. Plant Sci. 164:103-109.

Gezici, S. 2019. A study on turmeric (Curcuma longa L.): Multifunctional agents for the management of oxidative damage, neurodegeneration and cancer. Current Research In Pharmaceutical Sciences. 09(03): 46-53

Kennedy, D.O., and Wightman, E.L. 2011. Herbal extracts and phytochemicals: Plant secondary metabolites and the enhancement of human brain function. Adv. Nutr. 2: 32-50.

Kim, S., S. C. Ko, Y. S. Kim, S. K., Ha, H. Y. Park, Y. Park and Lee, S. H. 2019. Determination of Curcuma longa L.(Turmeric) leaf extraction conditions using response surface methodology to optimize extraction yield and antioxidant content. Journal of Food Quality. Article ID 7575206.

Kumar, A., M. Singh, P. P. Singh, S. K. Singh, P. Raj and Pandey, K. D. 2016. Antioxidant efficacy and curcumin content of turmeric (Curcuma-longa L.) flower. International Journal of Current Pharmaceutical Research. 8: 11-24.

Madhusankha, G.D.M.P., R.C.N. Thilakarathna, T. Liyanage and Navratne S.B. 2018. Analysis of curcumin content in Sri Lankan and Indian turmeric rhizomes and investigating its impact on the colour. International Journal of Food Science and Nutrition. 3(4):03-05.

Maizura, M., A. Aminah and Wan, A.W.M. 2011.Total phenolic content and antioxidant activity of Kusum (Polygonum minus), ginger (Zingiber officinale) and turmeric (Curcuma longa) extract. International Food Research Journal. 18: 2.

Namratha, K., P. Shenai, L. Chatra, P. K. Rao, K. M. Veena and Prabhu, R. V. 2013. Antioxidant and anticancer effects of curcumin-A review. Çağdaş Tıp Dergisi, 3(2).

Napal, D. G.N., M. Defago, G. Valladares and Palacios, S. 2010. Response of Epilachna paenulata to two flavonoids, Pinocembrin and quercetin, in a comparative study. J. Chem. Ecol. 36:898-904.

Sadasivam, S. and Manickam, 2008. Biochemical Methods, Third edition, New Age International Publishers, New Delhi, 202.

Verpoorte, R., Y. H. Choi and Kim, H. K. 2007. NMR-based metabolomics at work in phytochemistry. Phytochemistry. 6: 3-14.

Vishakha, B., K. Himanchal, L. Khyati, Aastha, P.S. Naresh and Vaishali. 2019 "Characterization of phenolic compounds of turmeric using TLC" published in Journal of Pharmacognosy and Phytochemistry. SP2: 994-998

Yan, S. W., and Asmah, R. 2010. Comparison of total phenolic contents and antioxidant activities of turmeric leaf, pandan leaf and torch ginger flower. International Food Research Journal. 17: 411-423.

Zulak K., D. Liscombe, H. Ashihara and Facchini, P. 2006. Alkaloids. Plant Secondary Metabolism in Diet and Human Health. Blackwell Publishing Oxford UK. Pp. 102-136.

\section{How to cite this article:}

Vishakha Burman, Vaishali, Khyati Lehari, Naresh Pratap Singh, Bijendra Singh, Pooran Chand, Jitender Singh and Sengar, R. S. 2020. Quantification of Total Phenolics and Curcumin Content in Different Turmeric Germplasm. Int.J.Curr.Microbiol.App.Sci. 9(11): 1753-1758. doi: https://doi.org/10.20546/ijcmas.2020.911.207 